Article

\title{
Challenges Addressed by Swedish Third-Party Logistics Providers Conducting Sustainable Logistics Business Cases
}

\author{
Maria Björklund ${ }^{1}$ and Helena Forslund ${ }^{2, *(D)}$ \\ 1 Department of Logistics and Quality Management, Linköping University, 58183 Linkoping, Sweden; \\ maria.bjorklund@liu.se \\ 2 Department of Management Accounting and Logistics, Linnaeus University, 35195 Vaxjo, Sweden \\ * Correspondence: helena.forslund@lnu.se
}

Received: 15 March 2019; Accepted: 1 May 2019; Published: 9 May 2019

\begin{abstract}
The sustainable logistics business case (SLBC) provides underlying argumentation to convince decision makers to approve initiatives within sustainable logistics. Little knowledge exists on how companies conduct SLBCs or the challenges that need to be addressed. The purpose of this paper is to explore how companies conduct SLBCs, to increase the understanding of how perceived challenges can be addressed. Potential challenges were identified in literature on business cases models in general and sustainable logistics business cases. As third-party logistics providers (3PL) are big contributors to emissions and often are responsible for designing logistics setups, they were focused in the empirical study. How SLBC were conducted was investigated based on interviews with managers responsible for conducting SLBCs and the responses triangulated with information derived from actual business cases. Despite the careful selection of 3PLs well ahead within the area, few challenges were perceived by the studied companies. This does not imply that challenges do not exist but can rather be described as a consequence of their pragmatic and inward-looking perspective. Examples of how to address challenges are provided. The compiled list of SLBC challenges provides an overview that was missing in literature.
\end{abstract}

Keywords: business case; third-party logistics provider; triple bottom line

\section{Introduction}

Traditionally, environmental and social initiatives have been associated with additional cost for the company; however, a paradigm shift has taken place linking sustainability initiatives to improved economic performance, e.g., [1-4]. This has also been demonstrated in some empirical studies focusing on, e.g., retailers [5] and manufacturers [1]. Even though more recent definitions of sustainability commonly include consideration of all three dimensions [6,7] and the call for such research is high [8], the sustainability dimensions are commonly addressed in isolation [9-11]. Conducting sustainable business cases, underlying arguments can be found to convince decision makers to approve environmental and/or social sustainability initiatives; see, e.g., [12]. Both practitioners and researchers found growing support for conducting sustainable business cases $[3,12,13]$.

Companies' considerations of sustainability are rising on the agenda of logistics and supply chain management research $[6,14]$. Transport and logistics activities are big contributors to emissions, and the demand for moving goods continues to grow [15]. However, few studies have focused on sustainable business cases in relation to logistics, raising a call among managers for such research. In a study of third-party logistical services by Wolf and Seuring [9], one of the cases measured environmental protection investments against their contribution to value creation. Björklund and Forslund [16] 
concluded that sustainable logistics business cases (SLBC) are of large importance to realize sustainable logistics investments, in competition with other investments. Conducting SLBCs are shown to be a company-internal activity, with little involvement of other companies, such as customers and suppliers, and as a result, there is little information exchange across company borders on how to carry out these SLBCs. As a result, practitioners call for guidance on how to carry out and design SLBCs. The SLBC can be described as the document as well as the underlying work needed to put forward a business case for, e.g., a potential investigation or change within logistics taking into consideration two or more sustainability dimensions (i.e., economy, environment and society).

Few concrete examples on how to conduct SLBCs were found. One explanation for this lack could be that conducting SLBCs is a very challenging task. These challenges are seldom described in literature, and an overview of these, as well as ways in which to address them, is missing. To increase the probability that sustainable logistics initiatives are realized, conducting strong SLBCs seems to be required. As a response to this knowledge gap, the purpose of this paper is to explore how companies conduct SLBCs, to increase the understanding of how perceived challenges can be addressed. The remaining paper is structured as follows; in Section 2, the frame of reference and methods are described. Section 3 elaborates upon the empirical results. Analysis and discussion are presented in Section 4, while Section 5 contains conclusions.

\section{Frame of Reference and Methods}

\subsection{Frame of Reference}

Literature on general business cases and especially sustainable logistics business cases including triple bottom-line considerations, have been important points of departure. Seven challenges associated with conducting an SLBC were identified and are presented below (developed from Björklund and Forslund [13]). As challenges are not always termed challenges, the list might not be complete nor conclusive. It is also acknowledged that challenges are sometimes interrelated. A compiled list of the challenges is found in the two first columns in Table 2 in the methods section.

\subsubsection{The Challenge of a Wide Range of Indicators}

A wide range of performance indicators can be included in a SLBC. Klumpp [7] stated many environmental indicators in third-party logistics providers (3PLs). An organization seldom has resources to target all potential indicators and the selection of for the company relevant indicators can be a challenge. Markley and Davis [17] were early to suggest indicators for sustainable supply chains targeting, e.g., employee satisfaction and governmental ratings of environmental performance. Bansal and Hoffman [18] state in their study of business case for designing closed-loop supply chain systems that both value creation (income indicators) and cost avoidance (cost indicators) should be included. Evangelista et al. [15] found a lack of a standard methodology for environmental performance measurement at 3PLs, and suggested that as future research. One of the most accepted standardized frameworks for reporting sustainability performance was developed by the Global Reporting Initiative (GRI) [19,20]. The framework includes several indicators: Economic (e.g., market presence and indirect economic impact), social (e.g., labor practices) and environmental (e.g., energy, emissions, effluents and waste). Govindan et al. [21] highlighted some additional economic and environmental indicators related to sustainable sourcing, such as costs for logistics, delivery reliability and environmental management systems. Additional social and economic indicators can also be found in Dos Santos et al. [5] and Winter and Knemeyer [11], including, e.g., social investments and market share. In a later systematic literature review on social responsibility in supply chain management, Abbasi [14] identifies safety, security and health as the most common indicators. 


\subsubsection{The Challenge of Measuring and Quantifying}

Measuring and quantifying play a central role in getting a holistic view of the triple bottom-line literature [4,17]. Wilson [20] points to the importance of measuring the performance to succeed with the triple bottom line. Suggestions for future research in quantifying especially 3PLs' environmental performance were provided by Evangelista et al. [15]. Wilhelm et al. [22] stated that the quantification of social impact is an important step towards social sustainability. The benefits from logistics-related sustainability initiatives can be categorized as tangible (benefits that can be measured) or intangible (benefits that cannot be measured) [3]. The economic dimension is more quantitative in nature compared to the social and environmental one [11]. Despite that, concrete material circumstances lie at the basis of the social dimension; the social phenomena themselves are immaterial and difficult to measure. To measure and quantify sustainability, especially aspects within the social dimension, can therefore be a challenge.

\subsubsection{The Challenge of Integrating Sustainability Dimensions}

The sustainability dimensions are interrelated and interdependent, and should be approached in an integrated manner $[6,8,10]$. In a review on the existing literature related to decision-support tools and performance measurement for sustainable supply chain management, Taticchi et al. [23] conclude that there is a need for integrated performance frameworks with new generation decision-support tools incorporating the sustainability dimensions. Wilson [20] indicates that the studied retailing companies did not integrate the three dimensions, but instead reported on each dimension separately. Despite the need for integration put forward in literature, this is seldom applied in practice, indicating that this could be a challenge for companies in conducting their SLBC.

\subsubsection{The Challenge of Trade-Offs between the Dimensions}

Taking a holistic approach means considering challenging trade-offs among the sustainability dimensions [23]. Dabhilkar et al. [24] studied sustainable sourcing, and investigated alignment of sustainability priorities and the impact on company economic performance. They found trade-offs between lower cost and higher social and environmental supplier compliance for noncritical components. At the same time Bals and Tate [8] called for more research addressing how sustainability indicators can be designed in relation to each other, and how to trade-off this in the design of sustainable supply chains. Winter and Knemeyer [11] pointed to potential trade-offs both within one dimension (individual vs. collective interests within the social dimension) and among the dimensions. Salzmann et al. [25] provided an overview of studies that focused on the trade-off between economic and environmental/social performance and showed differences in the direction of the causal sequence. Similar unclearness, in both trade-offs and win-wins between the environmental and economic dimension, was found in the literature review by Evangelista et al. [15] and in Klumpp [7]. It is therefore very challenging to first understand the complexity and possible trade-offs in the specific situation, and second to respect it and make the necessary choice.

One concrete example of a trade-off between two dimensions was described by Wilhelm et al. [22] in the study of a mobile phone's life cycle. Introducing social programs may lead to difficulties in managing production lines, and initially increasing the per unit manufacturing cost. In line with this, Gimenez et al. [1] claimed that social initiatives might not influence the triple bottom line in a straightforward way, as these initiatives could imply a better company reputation and indirectly increase sales while simultaneously increasing manufacturing costs. Gimenez et al. [1] also noted that their finding regarding the negative impact from social initiatives on the economic performance differs from some previous studies that argued for a positive, albeit modest, relation between social and economic performance. They concluded that the main reason for this difference is related to the scope where economic performance is measured in the different studies. They had limited their economic scope to the unit manufacturing cost, while the other studies took a broader scope including, e.g., total 
costs, sales and return on assets (ROA). Jensen et al. [26] concluded that by taking a closed-loop supply chain scope, it was possible to gain income from the value of waste. Waste, causing discarding costs from the retailer's perspective, was transformed to a value, as obsolete food products were turned into valuable input by implementing biogas technology at a bakery.

Some authors have claimed that a stand needs to be taken regarding the importance of the different dimensions in relation to each other. Sarkis and Dhavale [27] developed a model that provided various scenarios when evaluating sustainable suppliers by changing the importance of the weights of the three sustainability dimensions.

\subsubsection{The Challenge of the Influence from Stakeholders}

Stakeholder pressure is the most important driver for companies to improve sustainability [28]. In line with that, Winter and Knemeyer [11] and Wilhelm et al. [22] found that particularly the social dimension involves a wide range of stakeholders with different goals, demands and opinions and they may interpret the same situation differently. The influence from different stakeholders is also suggested as an important driving force for environmental performance within the logistics area (e.g., [17]). A similar situation is present in the sustainable supply chain management field; dealing with a wide range of objectives, criteria and elements in the supply chain [4]. Handling and prioritizing different stakeholders' objectives are therefore a challenge for companies when conducting SLBC. The recent study by Björklund and Forslund [16], however, found that sustainable business cases were conducted out of highly company-internal perspective.

\subsubsection{The Challenge of the Time Perspective}

To select a relevant time perspective for the SLBC can be a challenge, as included income and costs are affected by that selection. Wilhelm et al. [22] suggested an explanation for why social initiatives may negatively impact costs: Manufacturing cost is based on too short of a perspective. In addition, Klumpp [7] found difficulties in matching improvements in sustainability dimensions, as the effects can be related to different time periods. Wolf and Seuring [9] discussed the time dimension, stating that there was limited knowledge on how results of sustainability measurements impacted the company's present and future economy. In addition, Dyllick and Hockerts [29] recommend integrating short- and long-term aspects. Pagell and $\mathrm{Wu}[30]$ also discuss producing a profit over an extended period of time. Atkinson et al. [31] elaborate on the total life cycle cost measuring the length of time from the project's beginning until the product has paid back its development investments. Capital budgeting distributes an investment as cost over the economic lifespan, using different methods such as pay-back method or annuities [32].

\subsubsection{The Challenge of Contextual Considerations}

Contextual considerations can imply that companies apply sustainable business cases adjusted to their specific industry and position [25]. In their literature review, Taticchi et al. [23] concluded that there is a need to identify specific industry-related sustainability indicators. In addition to industry type, position and type of products, Wilhelm et al. [22] add yet other contextual considerations that can influence the applied social indicators, such as a company's values and motives. Furthermore, contextual considerations, such as company culture in terms of risk-taking and proactivity, also influence the internal support of sustainable supply chain initiatives [33]. No identified study focused on SLBCs in the 3PL sector. Altogether this implies that every company must start from their own contextual situation, and the challenge is to grasp that and design a SLBC without copying what other companies have done.

\subsection{Methods}

As no list of challenges existed, the challenges from literature were first discussed at two conferences, one logistics research conference and one conference with practitioners within furthermost 
the logistics industry. One previously identified challenge (the challenge of different weight between the sustainability dimensions) was then merged into the challenge of trade-offs between the sustainability dimensions. This increased construct validity. This study has an exploratory purpose, therefore empirical interaction with company respondents is critical, and interviewing managers is appropriate [34]. Klumpp [7] called for more empirical evidence in research on sustainability in logistics, as a lot of such research is non-empirical. As third-party logistics providers (3PL) are big contributors to emissions and often are responsible for designing logistics setups on behalf of manufacturers and retailers [7], they were addressed in the empirical study. The 3PLs studied were selected on the basis that they emphasized the importance of conducting SLBCs. They are known as forerunners in sustainable logistics, which indicates that they have been successful in providing arguments to convince decision makers. Other important selection criteria included good relationships based on trust and mutual research interest with the respondents. The geographical context implying 3PLs on the Swedish market was based on convenience [35] and the wish to interview representatives on-site.

As the purpose of this study was to explore how companies conduct SLBCs and address the perceived challenges, managers responsible of conducting SLBCs were targeted. In 3PL1 and 3PL3, the respondents were also responsible for supporting others who conducted SLBCs, providing a deep insight into SLBC challenges. In 3PL2 a second respondent (EQM) had the role of supporting (providing, e.g., calculations) as well as deciding on the outcome of SLBCs. As just one respondent was available in 3PL1 and 3PL3 (see Table 1), this is not seen as a case study. As the respondents anyway had different roles, challenges on operational to strategic levels were identified, hence providing complementary insights on perceived challenges, and implying data triangulation which increases construct validity.

Table 1. Companies and respondents studied.

\begin{tabular}{|c|c|c|}
\hline ID & Company Description & Respondent's Title \\
\hline 3PL1 & $\begin{array}{l}\text { Among the ten largest 3PLs in Sweden, } \\
\text { mainly operating regionally }\end{array}$ & CEO \\
\hline 3PL2 & $\begin{array}{c}\text { Among the three largest 3PLs on the } \\
\text { Swedish market }\end{array}$ & $\begin{array}{l}\text { Terminal manager (TM), Environmental } \\
\text { and quality manager (EQM) }\end{array}$ \\
\hline 3PL3 & $\begin{array}{c}\text { Among the largest 3PLs on the global } \\
\text { market }\end{array}$ & Environmental specialist \\
\hline
\end{tabular}

The data collection followed the procedures recommended by Yin [34] to increase construct validity. One such procedure is to base the interview guide on the literature, carefully operationalizing concepts studied. Table 2 outlines the challenges identified in the literature review and the operationalized interview questions derived for each challenge.

Opening with a description on how SLBCs are conducted, the focus was then placed on the challenges and how they were addressed. A successive probing was done, as the interviews were semi-structured, to not affect the responses. One 3PL shared documentation and examples of recently conducted SLBCs, while the other two could not for confidentiality reasons. However, one of them shared their SLBC guidelines. This documentation implied using multiple sources of evidence, another procedure to increase construct validity - as they complemented and broadened the interviewed managers' answers. Both the documentation and the interviews provided information regarding indicators applied, quantification, trade-offs and sustainability dimensions addressed, together forming the foundation of transcripts. The transcripts were sent to each respondent for verification directly after each interview, and they also received an early version of the paper. Most respondents did not have any comments on the transcripts, and if so, they were detailed such as the exact name of a computer program used. Having key respondents review the paper is a third way of increasing construct validity. A combination of deductive category assignment, using the interview questions derived from literature, and inductive category formation by repetitively scanning the transcripts, was 
carried out. As this qualitative analysis was carried out jointly by the researchers, thorough discussion on coding until full consensus was reached ensured inter-coder reliability. The reliability of the study was further ensured by clearly documenting coding, decisions and questions to allow for replication. To create more robust findings, a cross-company synthesis was carried out with a pattern-matching approach inspired by [34]. This implies to compare the empirically based pattern with the predicted, theoretical pattern and at the same time comparing the empirical cases with each other. The SLBC challenges and how they were addressed in the 3PLs were compared to each other and to the literature. All evidence was considered, plausible rival interpretations were addressed and focus was set on the most significant aspects, to secure internal validity. Altogether, construct validity and internal validity were satisfactory.

Table 2. Compiled list of challenges and operationalized interview guide.

\begin{tabular}{|c|c|c|}
\hline Challenge & Description & Questions to Address Empirically \\
\hline $\begin{array}{l}\text { A wide range of } \\
\text { indicators }\end{array}$ & $\begin{array}{l}\text { An organization seldom has resources to target all } \\
\text { potential indicators, and the selection of for the } \\
\text { company relevant indicators can be a challenge }\end{array}$ & $\begin{array}{l}\text { On what basis should the indicators be selected? } \\
\text { Which indicators are selected? } \\
\text { How can existing frameworks guide the selection of } \\
\text { indicators? } \\
\text { How can the indicators be categorized other than by } \\
\text { dimension? }\end{array}$ \\
\hline $\begin{array}{l}\text { Measuring and } \\
\text { quantifying }\end{array}$ & $\begin{array}{l}\text { To measure and quantify sustainability, especially } \\
\text { aspects within the more immaterial social dimension, } \\
\text { can be a challenge }\end{array}$ & $\begin{array}{l}\text { How can social and environmental performance be } \\
\text { measured and quantified? }\end{array}$ \\
\hline $\begin{array}{l}\text { Integrating the } \\
\text { dimensions }\end{array}$ & $\begin{array}{l}\text { The sustainability dimensions are interrelated and } \\
\text { interdependent, and it can be a challenge for } \\
\text { practitioners to integrate these }\end{array}$ & $\begin{array}{l}\text { Should the three sustainability dimensions be } \\
\text { integrated? } \\
\text { If yes, how can this be accomplished? }\end{array}$ \\
\hline Trade-offs & $\begin{array}{l}\text { In order to take a holistic approach, the challenge of } \\
\text { how to consider trade-offs among the sustainability } \\
\text { dimensions arises }\end{array}$ & $\begin{array}{l}\text { How are the trade-offs among the three sustainability } \\
\text { dimensions, as well as those within one dimension, } \\
\text { considered? } \\
\text { How can the selection of indicators influence } \\
\text { trade-offs? } \\
\text { Within which scope does environmental and social } \\
\text { performance occur? } \\
\text { Are the three dimensions equally important? } \\
\text { If not, how should the dimensions be weighted in } \\
\text { relation to each other? }\end{array}$ \\
\hline $\begin{array}{l}\text { Influence from } \\
\text { stakeholders }\end{array}$ & $\begin{array}{l}\text { To handle and prioritize the different stakeholders' } \\
\text { objectives and interpretations is a challenge when } \\
\text { conducting SLBC }\end{array}$ & $\begin{array}{l}\text { Which stakeholders influence the SLBC? } \\
\text { How can situations be handled when consensus } \\
\text { among stakeholders is not reached? }\end{array}$ \\
\hline $\begin{array}{l}\text { The time } \\
\text { perspective }\end{array}$ & $\begin{array}{l}\text { To select a relevant time perspective for the SLBC can } \\
\text { be a challenge, as included income and costs are } \\
\text { affected by that selection }\end{array}$ & $\begin{array}{l}\text { How is the time dimension considered? } \\
\text { Which capital budgeting methods are applied in } \\
\text { SLBCs? }\end{array}$ \\
\hline $\begin{array}{l}\text { Contextual } \\
\text { considerations }\end{array}$ & $\begin{array}{l}\text { The consideration and adoption of the SLBC to the } \\
\text { contextual setting in terms of, e.g., industry type, } \\
\text { position, type of products, values and motives can be } \\
\text { a challenge }\end{array}$ & $\begin{array}{l}\text { Which contextual considerations should be taken in } \\
\text { an SLBC? } \\
\text { How should this be carried out? }\end{array}$ \\
\hline
\end{tabular}

\section{Results}

Below the empirical findings from the 3PLs follow, initiated with a description of how the company conducts SLBC. Then information about how the company perceives (or does not perceive) and addresses the challenges follow.

\subsection{PL1}

3PL1 conducts business cases mainly for new customer assignments, and less frequently for internal investments. SLBCs are mainly applied before carrying out major changes and when the outcomes of larger changes are not intuitively clear. The reason for not conducting SLBC for "everything" is that it takes a lot of resources. There is no template for which indicators to include in an SLBC. Indicators are selected based on what is available in their GRI reporting. Additional indicators may be 
needed if customers require this; then a challenge can be to investigate and a decision can be made on whether it is possible to measure and quantify also unfamiliar indicators. 3PL1 is satisfied with the data to which they have access. One explanation could be that they focus largely on tangible indicators. For the economic dimension, data (transportation and driver costs) is collected as standard costs from SÅCalc (a widely used costing tool developed by the Swedish Association of Road Transport Companies). The fact that this tool is so widespread implies that no single company "dares" to question its output. Actual costs from their own bookkeeping are also used. Environmental data such as emissions, fill rate or cooling media consumption are available in their production system; they have a strong data collection system in real-time from most trucks. The social dimension is seldom included, but they have the potential to orally add it. Sometimes an image is included in the business case, built upon gut feeling and added orally toward the end. One example was when 3PL1 decided to start with a more environmentally-friendly fuel, HVO100. That business case was accepted due to large image benefits.

There is no striving for the SLBC to end up in one integrated number. No trade-offs are described between the sustainability dimensions on an overall level, as a saved kilometer implies saved cost and saved $\mathrm{CO}_{2}$. The same is said about social sustainability, where what is done for the employees, such as free exercising or education is not seen as a cost, but as an investment. SLBCs are important in identifying win-win initiatives. The economic dimension is most important, but to qualify for competing with cost, environmental sustainability is a hygiene factor. The respondent at 3PL1 was not aware of any situation when consensus was not reached on how to interpret potentials of different solutions. One explanation could be that few actors are involved; it is just two business area managers on their own or together with the CEO. The respondent does not see a challenge in the time perspective for a business case toward a customer, as this is the contract duration time. This sets the pay-back time, as a rule of thumb for a business case to be accepted. If the pay-back time is long, intangible aspects, such as image can gain credence. The SLBC regarding the accepted investment of solar panels on the warehouse had a pay-back time of 18 years.

\section{2. $3 P L 2$}

For ten years, 3PL2 has had a central unit that finances sustainability initiatives based upon SLBCs. One example was when a terminal wanted funding for a weather-related heating system for its loading platforms to make them safer. Its studied SLBC showed 70\% energy cost savings and improved worker safety. The SLBC is conducted using an application form with a standardized template. One of the first aspects to address in the template is the type of environmental gain, that is, if the case will result in (1) decreased outlets of climate gases, (2) decreased energy use, (3) decreased need for purchased energy from an external part or/and (4) other forms of decreased environmental impact (e.g., particles and sulphur dioxide). As a template is applied, there is no challenge to select which indicators to include. The template contains the following environmental indicators: Type of fuel or energy source, $\mathrm{CO}_{2}$ emissions ( $\mathrm{kg}$ ), energy use (unit can be selected, such as $\mathrm{kWh}$ in the SLBC studied), other climate gases (gas and unit can be selected) and a voluntary "other impacts or risk for the environment such as noise, waste and outlets to water". Economic indicators, such as total costs of the investment, additional costs, cost savings and pay-back time, are also included. Even though 3PL2 measures several social indicators, they are not included in the template and the social dimension is treated as "other information," together with reputation and communication value. For the template to function for different types of initiatives, it cannot be too specific.

Environmental impacts are quantified, but not translated into monetary value. The SLBC is conducted in a dialogue between managers and supporting environmental specialists, who are especially skilled in quantifications. Therefore, quantification is not perceived as a challenge. Other information is handled qualitatively as plus or minus at the end of the SLBC. No integration of the dimensions into one number is requested. 3PL2 sees no trade-offs between the economy and environment or between the environmental and social dimensions. Social and economic sustainability dimensions may, however, be challenging trade-offs as, e.g., collective agreements (social sustainability) often drive cost (economic 
sustainability). The social sustainability must not be decreased by any improvement of the two other dimensions; if that happens, the improvement will not be funded. If there is a trade-off for a suggested initiative, the timing may be wrong, as new technology can be expensive. This challenge also relates to the time perspective. A cross-functional group with sustainability, quality and environmental specialists discuss all applications. After a possible completion of the SBLC from the applying manager, a management group, consisting of managers for technology, infrastructure, internal and external communication, controllers and environment, decides. For many types of improvements, cooperation with stakeholders, such as property management and unions, are necessary, and this cooperation is perceived as a challenge. Furthermore, in the template it must be stated if the environmental data included has been received from suppliers or if they are based on calculations and estimations thus indicating a way to handle potential lack of direct information by carrying out its own, indirect calculations. The time perspective is handled by demanding a certain pay-back time, but it can be prolonged if the communication value is high, or if the company strategy is especially well supported. No challenges regarding contextual considerations are perceived.

\section{3. $3 P L 3$}

Investment needs can be driven from customer demands or internal needs. The company's investments policy places demand on carbon impact assessment for investments regarding both replacement of existing assets and new assets. An SLBC was conducted when considering investments in solar panels on a terminal. Despite an improved image, the environmental potentials were too low. Similar investments have been justified in, e.g., areas where the energy mix has a larger share of fossil energy. For all investments, 3PL3 is required to follow a given and detailed template designed at headquarter level, and the fact that indicators that are perceived as not relevant for a given investment still have to be provided in the SLBC is perceived as a challenge. The demands on the SLBC are very high; if some indicator is left out without arguments, the deciding department headquarter will return it. There is a need to be persistent, in that a no can be turned into a yes if the business case is made clearer the second time. The SLBC includes a high number of economic indicators, such as investment costs, leasing costs, pay-back time, overhead costs and tax rate. Regarding environmental indicators there is a narrow, but very deep, focus on $\mathrm{CO}_{2}$. The SLBC is supported by several internal guidelines on, e.g., which aspects to include depending on, e.g., the type of transport mode in focus and to decide if the calculation should be on scope 1, scope 2 or scope 3 level, thus including company internal activities or also external impacts. As the company has the aim of decreasing $\mathrm{CO}_{2}$ outlets, there is demand on calculating the reduction in both absolute numbers (total outlets) and relative numbers (outlets/parcel); e.g., as the number of parcels continues to grow, it is more difficult to reduce the absolute number, while the relative number often is easy to reduce due to large-scale advantages. Depending on mode of transport in focus, different assessment tools are applied. Even if $\mathrm{CO}_{2}$ is in focus, other forms of information are needed to carry out the assessment such as energy source, energy efficiency, fill rates and transport distances. The guidelines also include examples of SLBC and types of changes that influence $\mathrm{CO}_{2}$, such as changed network design, upgrading of the fleet and changed mode of transport, as well as guiding questions to ask and how to get support internally. This explains why quantification is not very challenging. The social dimension is not a part of the SLBC template. The environmental impact is not quantified in monetary terms.

The SLBC is designed to treat environmental and economic dimensions separately, and there is no interest in SLBCs that end up in one integrated number. A good result in one dimension can never justify a bad result in another. Each SLBC is decided on separately; even if 3PL3 provided several strong SLBCs and implemented sustainable improvements, this could not be used as an argument to justify a single, slightly costlier initiative.

The challenge of trade-offs between environmental and economic dimensions exists, as well as win-wins. As the company applies an $8 \%$ ROI, the costs due to tied-up capital are high with pay-back times longer than three years. Thus, the pay-back time terminates several potential initiatives, which is 
perceived as a challenge. Another aspect that can terminate a potential investment is if the change is not in line with the company's overall strategy. This was the situation when one Swedish division wanted to invest in a transport resource that enabled increased use of railways, which was against strategy. As the company acts globally, standardization is necessary and the conducting of SLBC cannot be influenced by the Swedish division. The Swedish division has little insight into the headquarters' decision-making, but due to the feedback they get, they trust it. A standardized follow up of the performance is carried out for all SLBCs.

\section{Analysis and Discussion}

Below the empirical insights gained are elaborated to shed light on how the challenges identified in the literature can be addressed. The 3PLs do not perceive all challenges from literature; some examples are shown in Table 3.

Table 3. Examples of challenges found in the studied third-party logistics providers (3PLs).

\begin{tabular}{cl}
\hline Challenges from Literature & \multicolumn{1}{c}{ Examples Found in the Studied 3PLs } \\
\hline A wide range of indicators & $\begin{array}{l}\text { The template states what indicators must be included, and indicators of no } \\
\text { relevance in a specific SLBC must therefore be calculated. (3PL3) }\end{array}$ \\
\hline Measuring and quantifying & $\begin{array}{l}\text { It can be a challenge to quantify new, sometimes unfamiliar, indicators } \\
\text { when customers require these to be included in the SLBC (3PL1) }\end{array}$ \\
\hline Trade-offs & $\begin{array}{l}\text { One challenge is the trade-off between the social and economic dimensions. } \\
\text { Social considerations, such as collective agreements, often drive cost. (3PL2) }\end{array}$ \\
\hline Influence from stakeholders & $\begin{array}{l}\text { To be able to quantify the impact on, e.g., rents and improved work } \\
\text { environment, cooperation with, e.g., property management and unions is } \\
\text { necessary. This cooperation is sometimes a challenge. (3PL2) }\end{array}$ \\
\hline The time perspective & $\begin{array}{l}\text { It is a challenge to identify the right timing for a change, as the investment } \\
\text { cost for, e.g., new technology depends on how new the technology is. (3PL2) } \\
\text { The time perspective is set by standard values on pay-back times and ROI, } \\
\text { and cases that in a longer time perspective can generate large income are } \\
\text { abandoned. (3PL3) }\end{array}$ \\
\hline
\end{tabular}

Two challenges from literature were not perceived by any of the respondents: Integrating the dimensions and contextual considerations. One explanation could be that there is no drive to integrate the dimensions and therefore this is not seen as a challenge. Furthermore, that contextual factors are not described as a challenge could be explained by contextual considerations, like organizational culture, which are not perceptible within the organization, and so are not perceived as a challenge. No challenges were perceived by all studied 3PLs. The low number of perceived challenges was at first unexpected, considering the selection of companies as forerunners when it comes to sustainable logistics, as well as the stress on the importance of SLBCs. However, one explanation as to why few challenges are perceived in practice could be that companies are pragmatic and adapt to available information, instead of trying to capture the entire complexity of sustainability. Without this ambition, several challenges disappear and conducting an SLBC is perceived as less challenging. Two companies (3PL2 and 3PL3) perceived most challenges, and these companies are characterized by having a formal SLBC template, placing high demand on the content of the SLBCs as well as involving different persons in the process of accepting the SLBCs.

The respondent in 3PL1 without a formal template seems more likely to ask "What information is available" than "What information is needed". This does not imply that the challenges do not exist in companies without templates, but rather it is an indication of simplification and avoiding the challenges. This is another unexpected finding, given the sampling criteria for the study. In addition, forerunners have a long way to go before SLBCs are conducted in a similar way as regular business cases. The analysis continues with each challenge. 


\subsection{Ways to Address the Challenge of a Wide Range of Indicators}

Even if literature suggests many sustainability indicators that can be included $[5,7,17,19]$, the companies studied have a more inward-looking perspective when selecting indicators. They take those that are available in the production system (all 3PLs), the ones customers demand (3PL1) or the ones decided upon on a headquarters level in the standardized SLBC template (3PL2 and 3PL3).

This leads to the challenge of the basis on which indicators should be selected. Several bases for selection have been identified among the companies studied, few of which were found in the literature, except for the connection to the standards in GRI, as called for by Evangelista et al. [15]. Could this pragmatic way of selecting indicators applied be the right way forward for companies, or is this a maturity issue that will develop over time? Furthermore, is there a need to guide the selection of indicators based on the frameworks mentioned in the literature? There is a need for development on how the social dimension is addressed in existing SLBCs, and these frameworks can be of great relevance in the identification of social indicators.

\subsection{Ways to Address the Challenge of Quantifying and Measuring}

In line with the literature, e.g., $[17,20]$, all companies studied acknowledge the importance of measuring sustainability performance, but they seldom see a need to quantify environmental and social indicators. Quantifying economical information is straightforward, often building upon standardized bookkeeping data or offers, applying indicators as, for example, size of investment, cost savings and pay-back time. This is in line with, e.g., Winter and Knemeyer [11] who describe the economical dimension as more quantitative in nature. The companies see no challenge in quantifying environmental information, except for 3PL1, which sometimes finds customer-suggested indicators challenging to measure. The 3PLs keep track of quantified indicators (e.g., emissions and fill rate) in their production system. 3PL2 and 3PL3 place demands that certain environmental indicators be quantified, such as $\mathrm{CO}_{2}$ emissions and energy use. These companies furthermore have supporting staff to do this. No company translates environmental indicators into monetary value. The social dimension is not quantified into indicators but considered in a qualitative or intangible way [3] such as 3PL1 and 3PL2 that sometimes include image or "reputation" as a social indicator. However, it is not experienced as a challenge. Most companies even have quantified social workforce indicators, which could be, but currently are not, included in the SLBC. In addition, this may be a "maturity" aspect; the environmental dimension was seldom included in business cases ten years ago. Altogether, the call for more research on quantifying 3PLs' environmental performance by Evangelista et al. [15] is confirmed to be highly relevant.

\subsection{Ways to Address the Challenge of Integrating Sustainability Dimensions}

Integrating sustainability dimensions is a demand expressed by, e.g., [7,8]. Research efforts have been made to support the presentation of one integrated number [23]. None of the studied companies integrated the three sustainability dimensions so that the SLBC ends in one number, which is in line with the retailing companies studied by Wilson [20]. It was found that the studied 3PLs expressed a lack of interest or requirements to do so, and showed no understanding of why this was needed. All companies in the current study seem to find more value in the possibility of discussing the pros and cons than in designing SLBCs that integrate all dimensions. It is still a challenge to decide to accept an SLBC, but the dialogue can provide several other benefits, such as knowledge transfer and continuous evaluation of the SLBC.

\subsection{Ways to Address the Challenge of Trade-Offs}

Even if the literature mentions the interdependence between the three sustainability dimensions and provides examples of trade-offs, see, e.g., [10,22,24], the studied companies always started to state the win-wins. 3PL2 described that a trade-off between economy and environment can appear 
because of how the challenge regarding time perspective was addressed. Trade-offs are seldom found between the environmental and economic dimension, strengthening the fact that the sample contains forerunners in sustainable logistics. Previous research has been unclear whether the environmental and social dimensions display trade-offs or win-wins, e.g., [7]. 3PL2 stated that there are trade-offs between the social and economic dimensions, as social considerations, such as collective agreements, often drive cost. No company exemplified or reflected upon trade-offs between the social and environmental dimensions, or trade-offs within one single dimension. 3PL2 and 3PL3 mention another important aspect: It is not enough that the SLBC shows win-wins among all three dimensions; the initiative must also be in line with the company's overall strategy to gain acceptance.

How the selection of indicators influence trade-offs was addressed primarily by the selection of economic indicators, such as pay-back time and how to value initiatives to improve the image. However, no challenges were raised regarding how the selection of environmental or social indicators influences the results of these dimensions overall. One explanation for this could be that the companies are not yet as mature when it comes to environmental and social performance measurement as compared to economic. There is a much deeper awareness of the selection of economic indicators and its impact on the results. When it comes to how to set the scope for environmental and social performance, which was suggested by Jensen et al. [26], the companies focused on the social impact within the company and the environmental impact caused by their operations unless, for example, a customer demanded a larger scope.

This study addresses the call from Bals and Tate [8] for additional research to address how indicators from all sustainability dimensions can relate to and balance each other. The studied companies showed that the sustainability dimensions were not always given the same weighting in the SLBC, a practice also identified in the literature [27]. In some companies, one dimension could be given a higher weight, such as the economical dimension, which was always the most important dimension for 3PL1. The environmental and social dimensions are treated as hygiene factors rather than given a specific weight. For example, no acceptance of an SLBC would result in an increased environmental impact (3PL1, 3PL3) or negative social impact (3PL2).

\subsection{Ways to Address the Challenge of Influencing Stakeholders}

In line with the literature, e.g., $[4,11]$, dealing with stakeholders' different values and objectives when conducting SLBC is sometimes perceived as a challenge. 3PL2 stated the importance of a close collaboration with property management and unions in several of their SLBCs to gain data and to take their values and objectives into account. 3PL2 also were asked to state in their SLBC which data that was collected from other companies or stakeholders, such as from suppliers. This is a sign of 3PL2's consciousness about the value of collecting data directly from the sources instead of making assessments. No examples were found when consensus was not reached in evaluating an SLBC. This could be due, in part, to the fact that no external stakeholders are included in deciding.

\subsection{Ways to Address the Challenge of Time Perspectives}

Time perspective is suggested as a challenge both in literature and by some companies studied. Perspectives that are too short-term offer an explanation of the negative trade-off between social initiatives and economy as indicated by Wilhelm et al. [22]. They also support the findings of Klumpp [7], who found difficulties in matching the effects in the three sustainability dimensions. This is supported by similar findings among the studied companies, such as demands on pay-back times within the contract period (3PL1). A high ROI that requires short pay-back times (3PL3) results in SLBCs indicating negative economic outcome for initiatives, even if longer term perspectives could be economically advantageous. Applying longer pay-back times can be seen as increased risk taking [33].

3PL1 and 3PL3 mentioned the need for follow up, as only time could tell whether the assumptions and assessment in the SLBC turned out to be correct. Similarities can be found with Wolf and Seuring [9], pointing to the limited knowledge on how changes influence the company's future 
economy. One response to this can be found in Dyllick and Hockerts [29], who argue for the integration of long- and short-term aspects. Even if the companies studied are aware of the influence time has, they do not consider the use of different time perspectives in their SLBC. This indicates that the time dimension is locked based on the indicators applied, for example pay-back times. Poor timing is a challenge for 3PL2, as new technology is often too expensive, but by waiting and redoing the same SLBC, an initiative can be economically viable. Both literature and the companies indicate a clear link between the time aspect and the economic dimension. No studied company used advanced capital budgeting methods [32], but used the simpler pay-back method to assess their investments.

\subsection{Ways to Address the Challenge of Contextual Considerations}

Literature, e.g., [23,25], suggested contextual differences related to industry. The limited sample size in our study may make this less valid. There are potential differences related to company size, where large 3PLs (3PL2 and 3PL3) differ from the smaller (3PL1), in terms of demands on complex and formalized SLBCs. Internal context, in the shape of lack of resources, was mentioned by 3PL1 mainly to explain the weak follow-up routines. The values of the company are a contextual factor mentioned by Wilhelm et al. [22]. The company's overall strategy and applied pay-back times can also be results of the values of the company. One aspect that potentially has a major influence when conducting SLBC is the drivers or motivating factors as to why the SLBC is being conducted. These drivers may be customer-driven (3PL1) or driven by internal environmental ambitions (3PL2, 3PL3).

\subsection{Ways to Address the Empirically Identified Challenge of Formalization}

One empirically identified challenge concerns the degree of SLBC formalization. 3PL1 adapts the complexity in the SLBC after the complexity of the initiative in a way where demand is lowered for smaller initiatives. In this way, fewer resources are put on evaluating smaller initiatives, which implies that small initiatives can also be realized. 3PL2 and 3PL3 have formalized templates for all SLBCs, which implies that all important information is included and that all initiatives are treated fairly. Combining these two methods, applying "scalable" SLBCs including both the fairness and credibility from formalization, and the flexibility and resource-efficiency from less formalization, were not considered by any of the studied companies. Applying such a hybrid would make it possible to realize also less common or predictable initiatives.

\subsection{Reflections over the Study Results}

Researchers make the world complex, turning every stone in their chase for challenges and finding several. Practitioners are more pragmatic and base their SLBC on available information, which implies that they do not perceive challenges or do not challenge themselves with those challenges identified by researchers. So, which is the road forward for practitioners? Maybe they need to question how the potential initiative or investment can affect other sustainability dimensions than the ones they normally follow internally or are found in their templates, and begin to ask the question "how will this initiative affect environmental and social sustainability in a more holistic way". The risk of moving problems is otherwise large, which can lead to unexpected problems in the future. To give sustainability dimensions higher priority and concretize them, one way forward could be to measure them to the same extent as everything else that is important and of value to the company is measured. Maybe the researchers are too ambitious when they want to see an SLBC that completely integrates the dimensions and ends up in one number. But without the possibility to compare effects from alternative initiatives, practitioners will not be aware about trade-offs. Are they so inward-looking that they do not realize that other stakeholders are affected by their initiatives? Do practitioners need to become more aware how change affects others such as customers and suppliers? This might inspire an expansion and strengthening of SLBCs with more effects, values and indicators. Practitioners could also be more aware about time perspectives. Some companies apply longer pay-back times for sustainable investments than for other investments, which can increase the understanding of and 
incentivize long-term effects. The researchers see a challenge in balancing their ambitions and support practitioners where they are, with the problems that are perceived.

\section{Conclusions}

As companies' considerations of sustainability are rising on the agenda of logistics research, e.g., $[7,14,15]$, the purpose of this research was to explore how companies conduct SLBCs to improve understanding of how perceived challenges can be addressed. Previous literature revealed challenges of a wide range of indicators, measuring and quantifying, integrating the three sustainability dimensions, trade-offs among the dimensions, the influence of stakeholders, the time perspective and contextual considerations. An empirical study in response to the call for such sustainability research from Klumpp [7] was carried out in 3PLs, in line with the suggestions of, e.g., Evangelista et al. [15]. The studied 3PLs did not require the SLBCs to result in one integrated figure, which reduces the perception of other challenges. It was interesting to find that the larger 3PLs with a formal SLBC template perceived more challenges, which can be a sign of maturity.

Ways of addressing the challenges identified in the literature were provided. Even though the companies were selected based on emphasizing the importance of conducting SLBCs, there was a gap between the literature and practice, suggesting a development potential in practice. Shevchenko et al. [28] noted the same phenomenon in discussing a discrepancy between literature and actual sustainability practice. They considered companies in a transition phase, where they still recognize or offset un-sustainability, rather than avoid it and create true sustainability. One reason could be too-low stakeholder pressure. Practice also shows the importance of spending the resources efficiently, many times resulting in a more pragmatic way of addressing the challenges that the literature suggests. One empirically generated challenge was the degree of SLBC formalization. A bit surprisingly, no company mentioned any context-related challenges from, e.g., the 3PL industry, which could potentially be low profitability, leading to increased demand to conduct detailed SLBCs or the propensity to simply accept initiatives with a very short pay-back time.

The compiled list of SLBC challenges is a contribution to literature, as such a list had not been previously assembled, and challenges are not always labelled challenges. It shows the complexity of conducting SLBCs and lays the foundation for further studies. It can also be used as a checklist for practitioners. Practical implications are found in the insights and understanding gained regarding how and why managers perceive and address the challenges identified. Innovative methods of addressing the challenges were provided, and these can be used as guidelines for managers. For logistics to become more sustainable, it is necessary for managers to be able to justify related initiatives.

Even if this exploratory study focuses on SLBCs applied by 3PLs, several findings and especially the list of challenges are likely to be have external validity for other types of companies and possibly also for other sustainable business cases. The standardized templates, used also for non-logistics initiatives in some companies, are one such example. Suggestions for further research were derived from the study. Quantified indicators for the social dimension were found to be underdeveloped and deserve deeper studies. A larger sample could reveal if other sectors, outside the 3PL scope, have similar challenges or have reached further when conducting SLBCs. It would be interesting to continue with a broader, survey-based study to provide a state-of-the-art description when conducting SLBCs. The development of scalable SLBCs, trading off standardization and flexibility, may contribute to an increased acceptance rate of sustainable logistics initiatives.

Author Contributions: Conceptualization, M.B. and H.F.; methodology, M.B. and H.F.; data collection, M.B. and H.F.; formal analysis, M.B. and H.F.; writing—original draft preparation, M.B. and H.F.; writing-review and editing, M.B. and H.F.; project administration, M.B.; funding acquisition, M.B. and H.F.

Funding: This research was funded by VINNOVA, Sweden's Innovation Agency, grant number 2014-03363.

Conflicts of Interest: The authors declare no conflict of interest. The funders had no role in the design of the study; in the collection, analyses, or interpretation of data; in the writing of the manuscript; or in the decision to publish the results. 


\section{References}

1. Gimenez, C.; Sierra, V.; Rodon, J. Sustainable operations: Their impact on the triple bottom line. Int. J. Prod. Econ. 2012, 140, 149-159. [CrossRef]

2. Liu, C.H.; Chen, M.-C.; Tu, Y.-H.; Wang, C.C. Constructing a sustainable service business model: An S-D logic-based integrated product service system (IPSS). Int. J. Phys. Distrib. Logist. Manag. 2014, 44, 80-97. [CrossRef]

3. Marchet, G.; Melacini, M.; Perotti, S. Environmental sustainability in logistics and freight transportation: A literature review and research agenda. J. Manuf. Technol. Manag. 2014, 25, 775-811. [CrossRef]

4. Santiteerakul, S.; Sekhari, A.; Bouras, A.; Sopadang, A. Sustainability performance measurement framework for supply chain management. Int. J. Prod. Dev. 2015, 20, 221-238. [CrossRef]

5. Dos Santos, M.A.O.; Svensson, G.; Padin, C. Indicators of sustainable business practices: Woolworths in South Africa. Supply Chain Manag. 2013, 18, 104-108. [CrossRef]

6. Touboulic, A.; Walker, H. Theories in sustainable supply chain management: A structured literature review. Int. J. Phys. Distrib. Logist. Manag. 2015, 45, 16-42. [CrossRef]

7. Klumpp, M. How to Achieve Supply Chain Sustainability Efficiently? Taming the Triple Bottom Line Split Business Cycle. Sustainability 2018, 10, 397. [CrossRef]

8. Bals, L.; Tate, W. Sustainable supply chain design in social businesses: Advancing the theory of supply chain. J. Bus. Logist. 2018, 39, 57-79. [CrossRef]

9. Wolf, C.; Seuring, S. Environmental impacts as buying criteria for third party logistical services. Int. J. Phys. Distrib. Logist. Manag. 2010, 40, 84-102. [CrossRef]

10. Gopalakrishnan, K.; Yusuf, Y.Y.; Musa, A.; Abubakar, T.; Ambursa, H.M. Sustainable supply chain management: A case study of British aerospace (BAE) systems. Int. J. Prod. Econ. 2012, 140, 193-203. [CrossRef]

11. Winter, M.; Knemeyer, A.M. Exploring the integration of sustainability and supply chain management: Current state and opportunities for future inquiry. Int. J. Phys. Distrib. Logist. Manag. 2013, 43, 18-38. [CrossRef]

12. Caroll, A.B.; Shabana, K.M. The business case for corporate social responsibility: A review of concepts, research and practice. Int. J. Manag. Rev. 2010, 12, 85-105. [CrossRef]

13. Björklund, M.; Forslund, H. Sustainable logistics business cases. In Proceedings of the WIP Presented at the 29th International NOFOMA Conference, Lund, Sweden, 9 June 2017.

14. Abbasi, M. Towards socially sustainable supply chains -themes and challenges. Eur. Bus. Rev. 2017, 29, 261-303. [CrossRef]

15. Evangelista, P.; Santoro, L.; Thomas, A. Environmental Sustainability in Third-Party Logistics Service Providers: A Systematic Literature Review from 2000-2016. Sustainability 2018, 10, 1627. [CrossRef]

16. Björklund, M.; Forslund, H. Exploring the sustainable logistics innovation process. Ind. Manag. Data Syst. 2018, 118, 204-217. [CrossRef]

17. Markley, M.J.; Davis, L. Exploring future competitive advantage through sustainable supply chains. Int. J. Phys. Distrib. Logist. Manag. 2007, 37, 763-774. [CrossRef]

18. Bansal, P.; Hoffman, A.J. The Oxford Handbook of the Business and the Natural Environment; Oxford University Press: New York, NY, USA, 2012.

19. Piecyk, M.I.; Björklund, M. Logistics service providers and corporate social responsibility: Sustainability reporting in the logistics industry. Int. J. Phys. Distrib. Logist. Manag. 2015, 45, 459-485. [CrossRef]

20. Wilson, J.P. The triple bottom line: Undertaking an economic, social, and environmental retail sustainability strategy. Int. J. Retail. Distrib. Manag. 2015, 43, 432-447. [CrossRef]

21. Govindan, K.; Khodaverdi, R.; Jafarian, A. A fuzzy multi criteria approach for measuring sustainability performance of a supplier based on triple bottom line approach. J. Clean. Prod. 2013, 47, 345-354. [CrossRef]

22. Wilhelm, M.; Hutchins, M.; Mars, C.; Benoit-Norris, C. An overview of social impacts and their corresponding improvement implications: A mobile phone case study. J. Clean. Prod. 2015, 102, 302-315. [CrossRef]

23. Taticchi, P.; Garengo, P.; Nudurupati, S.S.; Tonelli, F.; Pasqualino, R. A review of decision-support tools and performance measurement and sustainable supply chain management. Int. J. Prod. Res. 2015, 53, 6473-6494. [CrossRef] 
24. Dabhilkar, M.; Bengtsson, L.; Lakemond, N. Sustainable supply management as a purchasing capability: A power and independence perspective. Int. J. Oper. Prod. Manag. 2016, 36, 2-22. [CrossRef]

25. Salzmann, O.; Ionesco-Somers, A.; Steger, U. The business case for corporate sustainability: Literature review and research options. Eur. Manag. J. 2005, 23, 27-36. [CrossRef]

26. Jensen, J.K.; Munksgaard, K.B.; Arlbjörn, J.S. Chasing value offerings through green supply chain innovation. Eur. Bus. Rev. 2013, 25, 124-146. [CrossRef]

27. Sarkis, J.; Dhavale, D.G. Supplier selection for sustainable operations: A triple-bottom-line approach using a Bayesian framework. Int. J. Prod. Econ. 2015, 166, 177-191. [CrossRef]

28. Schevchenko, A.; Lévesque, M.; Pagell, M. Why firms delay reaching true sustainability. J. Manag. Stud. 2016, 53, 911-935. [CrossRef]

29. Dyllick, T.; Hockerts, K. Beyond the business case for corporate sustainability. Bus. Strateg. Environ. 2002, 11, 130-141. [CrossRef]

30. Pagell, M.; Wu, Z. Building a more complete theory of sustainable supply chain management using case studies of 10 exemplars. J. Supply Chain Manag. 2009, 45, 37-56. [CrossRef]

31. Atkinson, A.A.; Kaplan, R.S.; Matsumura, E.M.; Young, S.M. Management Accounting: Information for Decision Making and Strategy Execution; Pearson: Upper Saddle River, NJ, USA, 2012.

32. Brealey, R.A.; Myers, S.C.; Allen, F. Principles of Corporate Finance; McGraw-Hill Education: New York, NY, USA, 2008.

33. Gattiker, T.; Carter, C.; Huang, X.; Tate, W. Managerial commitment to sustainable supply chain management projects. J. Bus. Logist. 2014, 35, 318-337. [CrossRef]

34. Yin, R.K. The Abridged Version of Case Study Research: Design and Methods; Sage Publication: Thousand Oaks, CA, USA, 2014.

35. Bryman, A.; Bell, E. Business Research Methods, 3rd ed.; Oxford University Press: New York, NY, USA, 2011.

(C) 2019 by the authors. Licensee MDPI, Basel, Switzerland. This article is an open access article distributed under the terms and conditions of the Creative Commons Attribution (CC BY) license (http://creativecommons.org/licenses/by/4.0/). 